\title{
Kinerja Keuangan dengan metode Economic Value Added (EVA), Financial Value Added (FVA) dan Market Value Added (MVA) (Studi Pada Industri Telekomunikasi di Indonesia yang Terdaftar di BEI Tahun 2014-2018)
}

\author{
A. Kadim ${ }^{1)}$ \& Nardi Sunardi ${ }^{2}$ \\ 1) dosen Universitas Persada Indonesia YAl, email : sak kadim@yahoo.com \\ 2) dosen Universitas Pamulang, email : dosen01030@unpam.ac.id

\section{ARTICLES} \\ INFORMATION \\ ABSTRACT

\section{JURNAL SEKURITAS \\ (Saham, Ekonomi, Keuangan dan Investasi ) \\ Vol.3, No.2, Januari 2020 Halaman : $187-196$ \\ (c) LPPM \& Prodi Manajemen UNVERSITAS PAMULANG \\ ISSN (online) : 2581-2777 ISSN (print) : : 2581-2696 \\ Keyword : \\ Economic Value Added (EVA), Financial Value Added (FVA), Market Value Added (MVA), Kinerja Perusahaan \\ JEL. classification : Q15}

\section{Contact Author :} \\ PRODI MANAJEMEN UNPAM \\ JL.Surya Kencana No.1 \\ Pamulang Tangerang Selatan - \\ Banten \\ Telp. (021) 7412566, Fax (021) 7412491 \\ Email : \\ sekuritas@unpam.ac.id \\ EVA atau nilai tambah ekonomi adalah perbedaan laba \\ usaha setelah pajak (NOPAT) dan beban modal untuk periode \\ tersebut (yaitu, produk dari biaya modal perusahaan dan modal \\ yang diinvestasikan pada awal periode). Sedangkan FVA untuk \\ mengukur kinerja perusahaan yang mempertimbangkan \\ kontribusi dari fixed assets dalam menghasilkan keuntungan \\ bersih perusahaan dan MVA merupakan alat untuk mengukur \\ berapa banyak kekayaan suatu perusahaan yang telah \\ diciptakan untuk saat tertentu. Metode penelitian yang \\ digunakan adalah metode deskriptif kuantitatif dengan sampel \\ perusahaan telekomunikasi yang terdaftar di BEI. \\ Penelitian ini bertujuan untuk mengetahui kinerja keuangan \\ pada industri telekomunikasi yang terdaftar di Bursa Efek \\ Indonesia Periode 2014-2018 dengan pendekatan Economic \\ Value Added (EVA), Financial Value Added (FVA) dan Market \\ Value Added (MVA). Hasil penelitian ini menunjukkan bahwa \\ Perusahaan pada industri telekomunikasi dengan nilai EVA, \\ FVA dan MVA adalah positif yang berarti perusahaan berkinerja \\ baik. \\ EVA or Economic Value Added is the difference between \\ net operating profit after tax (NOPAT) and capital charges for \\ the period (ie, the product of cost of capital and invested capital \\ at the period). While FVA is to measure the company \\ performance that consider the contribution of fixed assets in \\ generating the company's net profit and MVA is a tool to \\ measure how much the company wealth that has been created \\ for a certain time. The method used is quantitative descriptive \\ method with the samples are telecommunications industry listed \\ in Indonesia Stock Exchange become the sample. \\ This study aims to find out the financial performance of the \\ telecommunications industry listing on Indonesia Stock \\ Exchange Period 2014-2018 with Economic Value Added \\ (EVA), Financial Value Added (FVA) dan Market Value Added \\ (MVA). The result of this research indicate that Company in the \\ telecommunications industry with EVA, FVA, dan MVA value \\ are positive means that it perform is good .
}

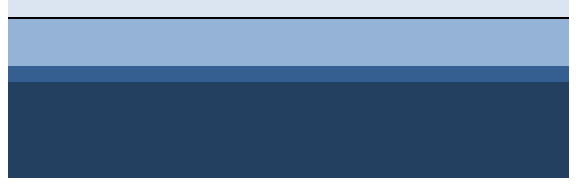




\section{A. PENDAHULUAN}

Dunia perekonomian modern saat ini telah mengalami banyak perkembangan, dan laporan keuangan telah menjadi bagian penting dan menjadi kebutuhan utama dalam proses pengambilan keputusan ekonomi dalam sebuah perusahaan. Evaluasi atau penilaian ternadap kinerja perusahaan, khususnya kinerja keuangan yang menjadi salah satu faktor penunjang perusahaan dalam menjalankan proses bisnis yang semakin kompetitif agar perusahaan mampu mempertahankan eksistensinya. Salah satu strategi untuk mengelola keuangan agar perusahaan tetap mampu bertahan dan bersaing yaitu dengan pengukuran kinerja keuangan .

Kinerja perusahaan pada umumnya diukur dengan rasio-rasio keuangan yang merupakan teknik atau metode untuk menganalisis laporan keuangan . Menurut Kartini (2008: 355) "Kinerja dan prestasi dengan rasio-rasio keuangan tidak dapat dipertanggungjawabkan, karena rasio keuangan yang dihasilkan sangat bergantung pada metode atau perlakuan akuntansi yang digunakan, dan penggunaan analisis rasio keuangan memiliki kelemahan antara lain: 1) Rasio keuangan tidak sesuai dengan perubahan tingkat harga. 2) Rasio keuangan sulit digunakan sebagai pembanding antara perusahaan sejenis, jika terdapat perbedaan metode akuntansi. 3) Rasio keuangan hanya menggambarkan keadaan sesaat, yaitu pada tanggal laporan keuangan dan periode pelaporan keuangan". Kelemahan utama rasio keuangan ini adalah mengabaikan unsur cost of capital atau biaya modal, sehingga sulit untuk menentukan dan mengukur nilai tambah yang tercipta dari perusahaan .

Untuk memperbaiki adanya kelemahan pada analisis rasio keuangan, para ahli kemudian mengembangkan metode lain sebagai alternatif agar dapat menunjukkan seluruh komponen harapan keuntungan yang terukur dalam biaya modal. Pengukuran terhadap kinerja keuangan perusahaan tersebut dapat dilakukan dengan pengukuran berdasarkan nilai tambah (Value Added) yang terdiri dari Economic Value Added (EVA), Financial Value Added (FMA) dan Market Value Added (MVA). EVA untuk menunjukkan produk dari biaya modal perusahaan dan modal yang diinvestasikan pada awal periode (Keown,2010:44 dalam T., 2017). MVA adalah perbedaan antara nilai pasar ekuitas perusahaan pada periode tertentu dengan nilai ekuitas yang dipasok para investornya. FVA untuk mengukur kontribusi dari fixed assets dalam menghasilkan keuntungan bersih perusahaan .

Objek penelitian dilakukan pada perusahaan go public yang bergerak dibidang telekomunikasi di Indonesia yang Listing di Bursa Efek Indonesia Tahun 2014-2018.

EVA atau nilai tambah ekonomi adalah perbedaan laba usaha setelah pajak (NOPAT) dan beban modal untuk periode tersebut (yaitu, produk dari biaya modal perusahaan dan modal yang diinvestasikan pada awal periode). Sedangkan FVA untuk mengukur kinerja perusahaan yang mempertimbangkan kontribusi dari fixed assets dalam menghasilkan keuntungan bersih perusahaan dan MVA merupakan alat untuk mengukur berapa banyak kekayaan suatu perusahaan yang telah diciptakan untuk saat tertentu (Sunardi, 2018). Metode penelitian yang digunakan adalah metode deskriptif kuantitatif dengan sampel beberapa perusahaan telekomunikasi di Indonesia yang Listing di Bursa Efek Indonesia Tahun 2014-2018 .

Berdasarkan permasalahan di atas maka penulis mencoba meneliti kinerja keuangan dengan menggunakan 3 metode yaitu EVA, FVA dan MVA.

Dari latar belakang tersebut, maka penulis mengambil judul Analisis Economic Value Added (EVA), Financial Value Added (FVA) dan Market Value Added (MVA) Sebagai Alat Penilaian Kinerja Keuangan (Studi Pada Industri Telekomunikasi yang terdaftar di BEI Tahun 2014-2018) . 
Berdasarkan latar belakang masalah di atas maka masalah yang akan dibahas dan dicari jawabannya dalam penelitian ini adalah :

1. Bagaimana Kinerja Keuangan Perusahaan pada industri telekomunikasi di Indonesia yang terdaftar di Bursa Efek Indonesia Tahun 2014-2018 berdasarkan metode Economic Value Added (EVA) ?

2. Bagaimana Kinerja Keuangan Perusahaan pada industri telekomunikasi di Indonesia yang terdaftar di Bursa Efek Indonesia Tahun 2014-2018 berdasarkan metode Financial Value Added (FVA)?

3. Bagaimana Kinerja Keuangan Perusahaan pada industri telekomunikasi di Indonesia yang terdaftar di Bursa Efek Indonesia Tahun 2014-2018 berdasarkan metode Market Value Added (MVA) ?

\section{B. KAJIAN LITERATUR}

\section{Kinerja Keuangan}

Kinerja dapat diartikan sebagai prestasi yang dicapai perusahaan dalam suatu periode tertentu yang mencerminkan tingkat kesehatan perusahaan tersebut (Winarni dan Sugiyarso, 2005:111). Kinerja keuangan merupakan suatu analisis dalam periode waktu tertentu untuk mengukur suatu gambaran kondisi perusahaan dengan menggunakanaturan pelaksanaan keuangan secara baik dan benar. Menurut Sunardi, N. (2018) mengatakan kinerja keuangan adalah penentuan suatu ukuran tertentu yang dapatmengukur keberhasilan suatu organisasi atau perusahaan dalam menghasilkan laba.Kinerja keuangan dapat diukur dengan cara menganalisis dan mengevaluasi laporan keuangan perusahaan .

\section{Economic Value Added (EVA)}

Economic Value Added senbagai tolak ukur kinerja keuangan dengan mengukur perbedaan antara pengembalian atas modal perusahaan dengan biaya modal (Young dan O'Byrne). Menurut Keown, dkk. rumus EVA adalah

\section{EVA $=$ NOPAT $-($ WACC $\times$ IC $)$}

"Langkah Perhitungan EVA

\begin{tabular}{|l|l|}
\hline \multicolumn{1}{|c|}{ Komponen EVA } & \multicolumn{1}{c|}{ Rumus } \\
\hline NOPAT & Pendapatan Usaha Bersih $(1-$ Tarif Pajak $)$ \\
\hline WACC & {$[(\mathrm{D}$ xrd $)(1$-tax $)+($ E $\times$ re $)]$} \\
\hline IC & (Total Hutang + Ekuitas $)-$ Hutang Jangka Pendek \\
\hline EVA & NOPAT $-($ WACC $\times$ IC $)$ \\
\hline
\end{tabular}

Keterangan:

NOPAT : Net Operating Profit After Tax (Laba operasi bersih setelah pajak)

WACC : Weighted Average Cost of Capital (Biaya modal rata - rata tertimbang)

D : Biaya modal hutang

rd : Persentase hutang dalam struktur modal Tax : Pajak

E : Biaya modal ekuitas

re : Persentase biaya modal pada struktur modal

IC : Invested Capital

EVA : Economic Value Added "

EVA > 0 maka menunjukkan telah terjadi proses nilai tambah pada perusahaan dan berhasil menciptakan nilai bagi penyedia dana. Tingkat pengembalian yang dihasilkan lebih besar daripada tingkat biaya modal atau tingkat biaya yang diharapkan investor atas investasi yang dilakukannya. EVA $=0$ menunjukkan posisi impas perusahaan karena semua laba digunakan untuk membayar kewajiban kepada penyedia dana baik kreditor maupun 
pemegang saham. EVA $<0$ menunjukkan tidak terjadinya proses nilai tambah karena laba yang tersedia tidak dapat memenuhi harapan para investor. Nilai perusahaan berkurang akibat tingkat pengembalian yang dihasilkan lebih rendah dari tingkat pengembalian yang diharapkan penyedia dana (investor) .

\section{Financial Value Added (FVA)}

"Financial Value Added merupakan metode dalam mengukur kinerja dan nilai tambah perusahaan. Metode ini mempertimbangkan kontribusi dari fixed assets dalam menghasilkan keuntungan bersih perusahaan (Iramani dan Febrian)". Menurut Rodrigues "perhitungan Financial Value Added (FVA) dapat diperoleh dengan menggunakan rumus sistemastis sebagai berikut;

$$
\text { FVA }=\text { NOPAT }-(\text { ED }-D)
$$

\section{Langkah Perhitungan FVA}

\begin{tabular}{|l|l|}
\hline \multicolumn{1}{|c|}{ Komponen FVA } & \multicolumn{1}{c|}{ Rumus } \\
\hline NOPAT & Pendapatan Usaha Bersih (1 - Tarif Pajak) \\
\hline ED & k $x$ TR \\
\hline FVA & NOPAT - (ED-D) \\
\hline
\end{tabular}

Keterangan:

NOPAT : Net Operating Profit After Tax (Laba operasi bersih setelah pajak)

ED : Biaya modal hutang

FVA : Financial Value Added

\section{Menghitung Equivalent Depreciations}

$\mathrm{ED}=\mathrm{k} \times \mathrm{TR}$

Dimana : ED = Equivalent Depreciations

$\mathrm{k}=$ Biaya Modal rata-rata tertimbang (WACC)

TR $($ Total Resource $)=$ Hutang Jangka Panjang + Total Equity"

\section{Mencari k adalah}

Menghitung WACC (Weighted Average Cost Of Capital)

Rumus : WACC $=[(D \times$ rd $)(1$-tax $)+(E \times$ re $)]$

Dimana :

$$
\text { Tingkat Modal }(\mathbf{D})=\frac{\text { Total Hutang }}{\text { Total Hutang dan Ekuitas }} \times 100 \%
$$

Nilai FVA $>0$ atau FVA bernilai positif menunjukkan terjadi nilai tambah financial bagi perusahaan. Nilai FVA $=0$ menunjukkan posisi impas. Nilai FVA $<0$ atau FVA bernilai negative menunjukkan tidak terjadi nilai tambah financial bagi perusahaan .

MVA positif, berarti pihak manajemen perusahaan telah mampu meningkatkan kekayaan perusahaan dan para pemegang saham atau bisa dikatakan kinerja perusahaan tersebut baik. MVA negatif, berarti pihak manajemen tidak mampu atau telah menurunkan kekayaan perusahaan dan kekayaan para pemegang saham, atau bisa dikatakan bahwa kinerja perusahaan tidak baik . 


\section{Market Value Added (MVA)}

Menurut Keown dkk. "Market Value Added (MVA) dapat diartikan sebagai perbedaan nilai pasar antara perusahaan dan modal yang telah diinvestasikan". MVA dapat dihitung sebagai berikut:"

\begin{tabular}{|c|c|}
\hline & MVA = Nilai perusahaan - Modal yang diinvestasikan \\
\hline & Langkah Perhitungan MVA \\
\hline Komponen MVA & Rumus \\
\hline NOPAT & Pendapatan Usaha Bersih (1 - Tarif Pajak) \\
\hline WACC & {$[(\mathrm{D} \times \mathrm{rd})(1-\operatorname{tax})+(\mathrm{E} \times \mathrm{re})]$} \\
\hline IC & (Total Hutang + Ekuitas) - Hutang Jangka Pendek \\
\hline EVA & NOPAT - (WACC $\times$ IC) \\
\hline
\end{tabular}

Keterangan:

NOPAT : Net Operating Profit After Tax (Laba operasi bersih setelah pajak)

WACC : Weighted Average Cost of Capital (Biaya modal rata - rata tertimbang)

D : Biaya modal hutang

rd : Persentase hutang dalam struktur modal Tax : Pajak

E : : Biaya modal ekuitas

re : Persentase biaya modal pada struktur modal

IC : Invested Capital

EVA : Economic Value Added"

MVA positif, berarti pihak manajemen perusahaan telah mampu meningkatkan kekayaan perusahaan dan para pemegang saham atau bisa dikatakan kinerja perusahaan tersebut baik. MVA negatif, berarti pihak manajemen tidak mampu atau telah menurunkan kekayaan perusahaan dan kekayaan para pemegang saham, atau bisa dikatakan bahwa kinerja perusahaan tidak baik .

\section{METODOLOGI PENELITIAN}

Penelitian ini merupakan penelitian deskriptif dengan pendekatan kuantitatif. maka dapat disusun kerangka pikir yang menggambarkan tentang analisis penilaian kinerja keuangan perusahaan dengan menggunakan metode Economic Value Added (EVA), Financial Value Added (FVA) dan Market Value Added (MVA) kemudian membuat kesimpulan sehingga dapat diketahui kinerja keuangannya .

Sampel dalam penelitian ini adalah beberapa perusahaan pada industri telekomunikasi di Indonesia yang terdaftar di Bursa Efek Indonesia periode 2014-2018 dan situs internet www.idx.co.id .

Teknik analisis data metode analisis data yang diperlukan secara kuantitatif dengan berdasarkan data skunder yang telah dikumpulkan. Analisis data dilakukan dengan mengelolah data-data yang diperoleh kemudian menganalisisnya. Tahapan-tahapan analisis data :

1. Mendapatkan data yang diperlukan dari laporan keuangan tahunan untuk periode 2014 sampai 2018

2. Menghitung komponen EVA

3. Menghitung komponen FVA

4. Menghitung komponen MVA

5. Menarik kesimpulan berdasarkan hasil perhitungan tersebut.

6. kontribusi/ wawasan kedepan dan pembahasannya secara ilmiah. 


\section{HASIL DAN PEMBAHASAN}

1. Hasil Analisis EVA (Economic Value Added) Untuk Mengukur Kinerja Keuangan Pada Industri Telekomunikasi di Indonesia yang terdaftar di BEI Tahun 2014-2018

Tabel 1.

Nilai Economic Value Added (EVA) pada industri telekomunikasi di Indonesia yang terdaftar di BEI Tahun 2014-2018

\begin{tabular}{|c|c|}
\hline Tahun & Nilai EVA \\
\hline 2014 & $(514.684 .002 .483)$ \\
\hline 2015 & 1.978 .484 .129 .235 \\
\hline 2016 & 922.333 .214 .645 \\
\hline 2017 & 1.142 .095 .810 .347 \\
\hline 2018 & 3.003 .894 .766 .520 \\
\hline Rata-rata & 1.306 .424 .783 .653 \\
\hline
\end{tabular}

Sumber: idx.co.id, data diolah (2019)

Berdasarkan tabel 1, dapat dilihat bahwa hasil perhitungan EVA untuk industri telekomunikasi di Indonesia yang terdaftar di BEI pada tahun 2014 adalah negatif yaitu sebesar -514.684.002.483, dan di tahun 2015 nilainya positif dan mengalami kenaikan menjadi 1.978.484.129.235. Kemudian di tahun 2016 mengalami penurunan, namun masih dengan nilai yang positif, yaitu 922.333.214.645. Di tahun 2017 mengalami kenaikan kembali menjadi 1.142.095.810.347 dengan nilai yang positif. Dan naik kembali di tahun 2018 dengan nilai positif menjadi 3.003.894.766.520. Rata-rata nilai EVA untuk industri telekomunikasi di Indonesia yang terdaftar di BEI Tahun 2014-2018 adalah positif yaitu sebesar 1.306.424.783.653.

2. Hasil Analisis FVA (Financial Value Added) Untuk Mengukur Kinerja Keuangan Pada Industri Telekomunikasi di Indonesia yang terdaftar di BEI Tahun 2014-2018

Tabel 2.

Nilai Financial Value Added (FVA) industri telekomunikasi di Indonesia yang terdaftar di BEI Tahun 2014-2018

\begin{tabular}{|c|c|}
\hline Tahun & Nilai FVA \\
\hline 2014 & 7.584 .151 .346 .712 \\
\hline 2015 & 10.747 .631 .129 .235 \\
\hline 2016 & 9.894 .903 .214 .645 \\
\hline 2017 & 9.994 .907 .810 .347 \\
\hline 2018 & 11.252 .894 .766 .520 \\
\hline Rata-rata & 9.894 .897 .653 .492 \\
\hline
\end{tabular}

Sumber: idx.co.id, data diolah (2019)

Berdasarkan tabel 2, dapat dilihat bahwa hasil perhitungan FVA untuk industri telekomunikasi di Indonesia yang terdaftar di BEI pada tahun 2014 adalah positif yaitu sebesar 7.584.151.346.712, dan di tahun 2015 nilainya juga positif dan mengalami kenaikan menjadi 10.747.631.129.235. Kemudian di tahun 2016 mengalami penurunan, namun masih dengan nilai yang positif, yaitu 9.894.903.214.645. Di tahun 2017 
mengalami kenaikan kembali namun sedikit menjadi 9.994.907.810.347 dengan nilai yang positif. Dan naik kembali di tahun 2018 dengan nilai positif menjadi 11.252.894.766.520. Rata-rata nilai FVA untuk industri telekomunikasi di Indonesia yang terdaftar di BEI dari tahun 2014-2018 adalah positif yaitu sebesar 9.894.897.653.492.

3. Hasil Analisis MVA (Market Value Added) Untuk Mengukur Kinerja Keuangan Pada Industri Telekomunikasi di Indonesia yang terdaftar di BEI Tahun 2014-2018

Tabel 3.

Nilai Market Value Added (FVA) industri telekomunikasi di Indonesia yang terdaftar di BEI dari tahun 2014-201

\begin{tabular}{|c|c|}
\hline Tahun & Nilai MVA \\
\hline 2014 & 8.354 .721 .000 .000 \\
\hline 2015 & 16.622 .609 .000 .000 \\
\hline 2016 & 20.871 .536 .000 .000 \\
\hline 2017 & 11.267 .186 .000 .000 \\
\hline 2018 & $(2.980 .125 .500 .000)$ \\
\hline Rata-rata & 10.827 .185 .300 .000 \\
\hline
\end{tabular}

Sumber: idx.co.id, data diolah (2019)

Berdasarkan tabel 3, dapat dilihat bahwa hasil perhitungan MVA untuk industri telekomunikasi di Indonesia yang terdaftar di BEI dari tahun 2014-2018 pada tahun 2014 adalah positif yaitu sebesar 8.354.721.000.000, dan di tahun 2015 nilainya juga positif dan mengalami kenaikan menjadi 16.622.609.000.000. Kemudian di tahun 2016 mengalami kenaikan dengan nilai yang positif, yaitu 20.871.536.000.000. Di tahun 2017 mengalami penurunan menjadi 11.267.186.000.000 dengan nilai yang positif. Dan turun cukup signifikan di tahun 2018 dengan nilai negatif menjadi -2.980.125.500.000. Ratarata nilai MVA untuk industri telekomunikasi di Indonesia yang terdaftar di BEI dari tahun 2014-2018 adalah positif yaitu sebesar 10.827.185.300.000.

4. Analisis dan Interpretasi Kinerja Keuangan Metode Economic Value Added (EVA), Financial Value Added (FVA) dan Market Value Added (MVA) Industri Telekomunikasi di Indonesia yang terdaftar di BEI Tahun 2014-2018

Tabel 4.

Rekapitulasi Kinerja Keuangan Perusahaan industri telekomunikasi di Indonesia yang terdaftar di BEI dari tahun 2014-2018 (Dalam Milyaran Rupiah)

\begin{tabular}{|c|c|c|c|c|c|c|}
\hline \multirow{2}{*}{ Variabel } & \multicolumn{7}{|c|}{ Periode } & \multirow{2}{*}{ Rata-rata } \\
\cline { 2 - 6 } & $\mathbf{2 0 1 4}$ & $\mathbf{2 0 1 5}$ & $\mathbf{2 0 1 6}$ & $\mathbf{2 0 1 7}$ & $\mathbf{2 0 1 8}$ & \\
\hline (EVA) & - & + & + & + & + & $1.306,425$ \\
\hline (FVA) & + & + & + & + & + & $9.894,89$ \\
\hline (MVA) & + & + & + & + & - & $10.827,185$ \\
\hline
\end{tabular}

Sumber: idx.co.id, Data Diolah (2019)

Berdasarkan tabel 4 rekapitulasi kinerja Keuangan Perusahaan industri telekomunikasi di Indonesia yang terdaftar di BEI dari tahun 2014-2018 Periode 2014 terlihat Economic Value Added (EVA) menunjukkan nilai negatif artinya kondisi keuangan 
perusahaan berkinerja tidak baik, namun di tahun 2015-2018 menunjukkan nilai EVA yang positif, artinya kinerja keuangan pada industri telekomunikasi di Indonesia yang terdaftar di BEI dari tahun 2014-2018 memiliki kinerja keuangan yang baik. Dan nilai ratarata EVA sebesar $1.306,425$ dengan nilai yang positif, artinya kinerja keuangan industri telekomunikasi di Indonesia yang terdaftar di BEI dari tahun 2014-2018 dilihat dari nilai EVA di tahun 2014-2018 secara keseluruhan adalah baik .

Financial Value Added (FVA) tahun 2014-2018 menunjukkan nilai FVA yang positif, artinya kinerja keuangan pada industri telekomunikasi di Indonesia yang terdaftar di BEI dari tahun 2014-2018 memiliki kinerja keuangan yang baik. Dan nilai rata-rata FVA sebesar 9.894,89 dengan nilai yang positif, artinya kinerja keuangan industri telekomunikasi di Indonesia yang terdaftar di BEI dari tahun 2014-2018 dilihat dari nilai FVA secara keseluruhan di tahun 2014-2018 adalah baik .

Berdasarkan tabel 4 rekapitulasi kinerja Keuangan Perusahaan industri telekomunikasi di Indonesia yang terdaftar di BEl dari tahun 2014-2018 Periode 20142017 terlihat Market Value Added (MVA) menunjukkan nilai MVA yang positif, artinya kinerja keuangan pada industri telekomunikasi di Indonesia yang terdaftar di BEI tersebut memiliki kinerja keuangan yang baik. Sedangkan di tahun 2018 nilai MVA negative, yang artinya kinerja keuangan perusahaan sedang tidak baik. Dan nilai rata-rata MVA sebesar $10.827,185$ dengan nilai yang positif, artinya kinerja keuangan industri telekomunikasi di Indonesia yang terdaftar di BEI dari tahun 2014-2018 dilihat dari nilai MVA di tahun 20142018 secara keseluruhan adalah baik

\section{E. KESIMPULAN}

Economic Value Added (EVA), Financial Value Added (FVA) dan Market Value Added (MVA) beberapa perusahaan industri telekomunikasi di Indonesia yang terdaftar di BEI dari tahun 2014-2018 sebagai berikut :

a. Analisis Economic Value Added (EVA), untuk penilaian Kinerja Keuangan Periode 2014-2018, nilai rata-rata EVA perusahaan industri telekomunikasi di Indonesia yang terdaftar di BEI dari tahun 2014-2018, adalah positif ini berarti perusahaan mampu memberikan nilai tambah bagi para pemegang sahamnya karena nilai EVA bernilai positif (EVA > 0) sehingga dikatakan berkinerja baik .

b. Analisis Financial Value Added (FVA) untuk penilaian Kinerja Keuangan Periode 2014-2018, untuk penilaian Kinerja Keuangan, nilai rata-rata EVA perusahaan industri telekomunikasi di Indonesia yang terdaftar di BEI dari tahun 2014-2018, adalah positif ini berarti perusahaan mampu memberikan nilai tambah financial bagi para pemegang sahamnya karena nilai FVA bernilai positif (FVA >0) sehingga dikatakan berkinerja baik .

c. Analisis Market Value Added (MVA) untuk penilaian Kinerja Keuangan, nilai rata-rata MVA perusahaan industri telekomunikasi di Indonesia yang terdaftar di BEI dari tahun 2014-2018, pada tahun 2014-2018 adalah positif ini berarti perusahaan mampu memberikan nilai tambah pasar bagi para pemegang sahamnya karena nilai MVA bernilai positif (MVA > 0) sehingga dikatakan berkinerja baik . 


\section{DAFTAR PUSTAKA}

A. Erika dan A. Astiti Chandra, "Penilaian Tingkat Kesehatan Bank: Pendekatan CAMEL dan RGEC (Studi Pada Bank Maybank Syariah Indonesia Periode 2011-2016)," Jurnal Akuntansi dan Keuangan Islam., vol. 6, no. 2, pp. 189-207, 2018.

Abdul Kadim, K., Nardi Sunardi, S., Hendro Waryanto, W., Dessy Adelin, A., \& Endang Kusmana, K. (2018). The Effects Of Bank Soundness With The RGEC Approach (Risk Profile, Good Corporate Governance, Earnings, Capital) Of Leverage And Its Implications On Company's Value Of State Bank In Indonesia For The Period Of 20122016. IJER (International Journal of Economic Research), 15(11), 41-52.

Bank Indonesia. (2012). Peraturan Bank Indonesia Nomor: 14/2/PBI/2012 tentang Perubahan atas PBI Nomor:11/11/PBI/2009 tentang Kegiatan Alat Pembayaran dengan Menggunakan Kartu.

H. Theresia Vania dan N. Nila Firdaus, "Analisis Tingkat Kesehatan Bank Berdasarkan Metode Risk Based Bank Rating (Studi Pada Bank Umum Konvensional Di Indonesia Periode 2014-2016)," Jurnal Administrasi Bisnis (JAB)., vol. 57, no. 1, 2018.

Jakarta: Otoritas Jasa Keuangan.

Jumingan. (2014). Analisis Laporan Keuangan.Jakarta :BumiAksara

Kartini, Gatot Hermawan. (2008). Economic Value Added dan Market Value Added terhadap Return Saham. Jurnal Keuangan dan Perbankan, Volume 12 No.3 September 2008: 355-368. Universitas Islam Indonesia, Yogyakarta.

Kasmir. (2013). Bank dan Lembaga Keuangan Lainnya. PT Raja Grafindo Persada

Nardi Sunardi, E. A., Kadim, A., Tumanggor, M., \& Oktrima, B. (2018). Effects Of The Bank Soundness With The Rbbr Approach (Risk Base Bank Rating) Of Cost Efficiency And Its Implications On Sharia Bank Performance In Indonesia For The Period Of 20122016. International Journal of Economic Research, 15(1).

Nataly, Daisy, 2011, "Knowledge Management", Makalah pada MB IPB, Bogor 18 Maret 2011.

Nuraini,Topowijono dan F.Yaningwati (2015), Penilaian Kinerja Keuangan Perusahaan Menggunakan Analisis Return On Investment (ROI) Dengan Pendekatan Du Pont System Dan Residual Income (RI) (Studi Pada Perusahaan Kosmetik Dan Keperluan Rumah Tangga Yang Listing Di Bursa Efek Indonesia Tahun 2011-2013), Jurnal Administrasi Bisnis (JAB)|Vol. 26 No. 2 September 2015.

Organization for Economic Co-operation and Development (OECD). 1999. International Symposium on Measuring and Reporting Intellectual Capital, Experience, Issues and Prospects. Amsterdam, 9-11 June 1999.

Otoritas Jasa Keuangan, 2015, Roadmap Perbankan Syariah Indonesia 2015-2019, Departemen Perbankan Syariah OJK, Jakarta

Pangestika, Styfanda, 2015, Analisis Estimasi Moel Regresi Data Panel Dengan Pendekatan Common Effect Model (CEM), Fixed Effect Model (FEM), dan Random Effect Model (REM), Skripsi Fakultas MIPA Universitas Negeri Semarang, tidak dipublikasikan

Peraturan Perundang-undangan, 1992, Undang-undang Republik Indonesia Tahun 1992 Tentang Perbankan, DPR-RI, Jakarta

Riyadi Slamet, 2006. Banking Assets and Liability Management (Edisi Ketiga). Jakarta: Lembaga Penerbit Fakultas Ekonomi Universitas Indonesia, 2006.

Rose, Peter S and Sylvia C Hudgins (2010) Bank Management and Financial Services. New York : Mc Grow Hill

Sunardi, N. (2018). Analisis Economic Value Added (Eva), Financial Value Added (FVA) Dan Market Value Added (MVA) Dengan Time Series Approach Sebagai Alat Penilaian Kinerja Keuangan (Studi Pada Industri Konstruksi (BUMN) di Indonesia Yang Listing di BEI Tahun 2013-2017). Jurnal SEKURITAS (Saham, Ekonomi, Keuangan dan Investasi), 2(1).

Jurnal SEKURITAS (Saham, Ekonomi, Keuangan dan Investasi ), Vol.3, No.2 , Januari 2020....... 195 
T., Nuryani. (2017). Analisis Pengukuran Kinerja Keuangan Perusahaan Menggunakan Value Based (EVA, MVA DAN FVA) dan Financial Ratio (Market Value Ratio, Provitability Ratio dan Financial Leverage) pada Perusahaan Subsektor Jasa Transportasi Terdaftar di BEI Periode 2010-2016.

Taswan. 2010. Manajemen Perbankan, Konsep, Teknik, dan Aplikasi. Edisi Kedua. Yogyakarta : UPP STIM YKPN.

Vandi Surya Winata 2016, Penggunaan Analisis Kinerja Keuangan Perusahaan Dengan Pendekatan Economic Value Added (Eva) Dan Market Value Added (MVA) Pada Perusahaan Manufaktur Yang Go Public Di Bursa Efek Indonesia Tahun 2012-2015, eJournal S1 Ak Universitas Pendidikan Ganesha, Jurusan Akuntansi Program S1 (Vol: 6 No: 3 Tahun 2016)

Viandina Puspita, 2015 pengaruh economic value added (EVA) dan market value added (MVA) terhadap harga saham pada perusahaan kelompok lq-45 di bursa efek indonesia, Jembatan - Jurnal IImiah Manajemen Bisnis Dan Terapan Tahun XII No 2, Oktober 2015

White, D. Steven, Gunasekaran, Angappa. Ariguzo, Godwin C. 2013, "The Structural Components of a Knowledge-based Economy", Int. J. Business Innovation and Research, Vol. 7, No. 4, hal. 504-518

Winarni, F dan Sugiyarso, G. (2005). Manajemen Keuangan. Yogyakarta: Liberty.

Zuhal. 2010. Knowledge \& Inovation sebagai Platform Kekuatan Daya Saing. PT. Gramedia Pustaka Utama, Jakarta 